\title{
Using life cycle sustainability assessment to trade off sourcing strategies for humanitarian relief items
}

\author{
Elisah Antonia van $\operatorname{Kempen}^{1} \cdot$ Eirini Spiliotopoulou $^{1} \cdot$ Goran Stojanovski $^{2} \cdot$ Sander de Leeuw $^{1,3}$
}

Received: 9 February 2016/Accepted: 29 November 2016/Published online: 17 December 2016

(C) The Author(s) 2016. This article is published with open access at Springerlink.com

\begin{abstract}
Purpose While interest in supply chain sustainability has risen over the past few years in academic and business worlds, very little research has been conducted on sustainability in humanitarian supply chains, specifically. This study aims to contribute to the development of the field by conducting a life cycle sustainability analysis (LCSA) of sourcing scenarios for a core relief item in a humanitarian supply chain.

Methods This paper is structured according to the LCSA framework developed by Guinée et al. (Environ Sci Technol 45(1):90-96, 2011). The relief item analyzed is a kitchen set supplied by a UN agency. Environmental, social, and economic impacts of two sourcing scenarios for a kitchen set are mapped: one international and one local. Sources of data include interviews, company records, and online databases. Results are analyzed using the ReCiPe method to assess environmental impact and the United Nations Environmental Programme (UNEP)/Society of Environmental Toxicology and Chemistry (SETAC) guidelines to assess social impact.
\end{abstract}

Responsible editor: Trakarn Prapaspongsa

Electronic supplementary material The online version of this article (doi:10.1007/s11367-016-1245-z) contains supplementary material, which is available to authorized users.

Sander de Leeuw

sander.de.leeuw@vu.nl

1 Faculty of Economics and Business Administration, Department of Information Logistics and Innovation, VU University Amsterdam, De Boelelaan 1105, 1081 HV Amsterdam, The Netherlands

2 Division of Emergency, Security and Supply, United Nations High Commissioner for Refugees, Ipoly Utca 5 b, c, d, Budapest 1133 , Hungary

3 Nottingham Business School, Nottingham Trent University, Burton Street, Nottingham NG1 4BU, UK
Results and discussion We show how LCSA can be used to map the sustainability of two sourcing scenarios for kitchen sets in a humanitarian supply chain along triple bottom line dimensions. We report findings on sourcing scenarios for distribution to two refugee camps in Kenya: one from a supplier in India and one from a supplier in Kenya. We use an environmental life cycle analysis (LCA), a social LCA, and a life cycle costing (LCC) to analyze differences and similarities. We find that local sourcing is preferred over international sourcing on two out of the three sustainability dimensionsenvironmental and social impacts. Humanitarian organizations may further use this paper as a guideline to develop their own sustainability assessments of supply chain scenarios. Conclusions The results of our study provide a fresh, sustainability-focused perspective on the debate over international vs. local procurement. This paper is the first to apply LCSA to a humanitarian context. It also addresses a void in the sourcing literature by determining the sustainability impacts of different sourcing strategies. The study evaluates only two sourcing options and also uses a limited number of data sources.

Keywords Core relief items $\cdot$ Humanitarian supply chains . International/local sourcing $\cdot$ LCSA $\cdot$ Sourcing strategies · Triple bottom line

\section{Introduction}

Sustainability has become an increasingly important issue in commercial supply chains (Golicic and Smith 2013) as businesses now realize that it can lead to cost savings, improved compliance, and competitive advantage (Seuring and Müller 2008). Sustainability is often captured in the literature by the triple bottom line: people, planet, and profit (Gimenez et al. 
2012). Seuring and Müller (2008) summarize sustainable supply chain management as "the management of material, information and capital flows as well as cooperation among companies along the supply chain while taking goals from all three dimensions of sustainable development, i.e., economic, environmental and social, into account which are derived from customer and stakeholder requirements" (p. 1700).

In contrast, very little research has been conducted in the area of sustainable supply chain management in humanitarian supply chains (Haavisto and Kovács 2012; Haavisto and Kovács 2014). This is despite the fact that their processes for planning, implementing, and controlling the flows of goods and related information are similar to those used in commercial supply chain management (Thomas and Kopczak 2005). Although the triple bottom line is a well-known concept in commercial supply chains, it is an underdeveloped area in humanitarian supply chain management (Haavisto and Kovács 2012). While to some extent the socioeconomic impacts of vendor selection have been researched, environmental impacts (including electricity usage or fuel consumption) and social impacts (such as child labor) have been touched upon only rarely (Haavisto and Kovács 2012).

Several crucial characteristics of humanitarian supply chain management (SCM) are not evident in commercial supply chains, including the following: uncertainty with regard to the timing, location, type, and size of demand; sudden spikes in demand for a wide variety of supplies accompanied by short lead times; high stakes associated with the timeliness of deliveries; and lack of resources (Kovács and Spens 2009). These characteristics make supply chain management in a humanitarian context more challenging than in a commercial business environment. A life cycle sustainability assessment (LCSA) can serve as a tool to help organizations identify the environmental, social, and economic impacts of their activities (Klöpffer 2008). LCSA is a more inclusive extension of life cycle analysis (LCA), which focuses on the environmental impacts associated with the products, processes, and activities of an organization (Svoboda 1995). In this paper, we use LCSA to assess two procurement scenarios in terms of their positive impact on the environment, society, and economy. We analyze a typical sourcing trade-off in humanitarian supply chains: sourcing items from local suppliers (in the area where the items are used) or sourcing items from global suppliers (on a different continent) (cf. Apte 2010; Kunz and Reiner 2012; Balcik and Ak 2014). We focus on the delivery of kitchen sets to two refugee camps in Kenya, Dadaab and Kakuma, which are among the world's largest refugee communities. We analyze one scenario in which items are sourced from a local supplier in Nairobi (Kenya) and another in which items are sourced internationally from a supplier in India. This paper contributes to the sustainability literature in humanitarian logistics by demonstrating the ability of LCSA to guide sourcing decisions. Furthermore, our results may help humanitarian organizations initiate discussions on the social and environmental impacts of their operations and determine whether to source goods locally or internationally.

In the next section, we review the literature on procurement and sustainability in supply chains. This section is followed by an outline of our methodology (based on the LCSA framework of Guinée et al. 2011). Thereafter, we present the results of an LCSA of two sourcing scenarios: international and local. Finally, we discuss the results and implications.

\section{Literature review}

\subsection{Procurement in humanitarian organizations}

Humanitarian logistics activities can be divided into two main categories: immediate disaster relief or long-term continuous aid work, generally following disasters (Falasca and Zobel 2011). The literature on humanitarian logistics is biased towards disaster relief (Venkatesh et al. 2014) and focuses primarily on the prepositioning of supplies (Davis et al. 2013). In contrast, our work is concerned with procurement of developmental aid. Although it is of great importance, there are few publications focused on humanitarian procurement (Duran et al. 2013). Around 15 years ago, it was estimated that humanitarian organizations annually procured US $\$ 50$ billion in items (Taupiac 2001). Procurement for development aid concerns efforts aimed at long-term social and economic development (Taupiac 2001). Within this stream, Falasca and Zobel (2011) introduce a two-stage stochastic programming model for the humanitarian procurement process. Ertem et al. (2010) present an auction-based framework for allocating humanitarian procurements, which they evaluate using a simulation model. We focus on the trade-off between procurement from the region in which a disaster takes place versus from an international source. In disaster relief, local procurement has the advantage of faster delivery times and lower transportation costs (PAHO 2001). At the same time, it can result in shortages in the local market (if local suppliers do not have the required quantity and quality), local competition between humanitarian organizations, and price inflation (PAHO 2001; Duran et al. 2013). International procurement enables access to larger quantities, lower prices, and consistent quality, which is why disaster relief humanitarian procurement is mostly done internationally (Falasca and Zobel 2011). However, this need not be the case with continuous aid.

\subsection{Sustainability and humanitarian supply chains/sourcing}

Humanitarian organizations are increasingly pressed to develop solutions that are sustainable in terms of their environmental, social, and economic impact (Kovács and Spens 2011a). 
However, the field of sustainability research in humanitarian supply chains is in its infancy (Kovács and Spens 2011b). Beneficiary empowerment (e.g., aid that encourages beneficiaries to make decisions themselves) and community-based supply chain design (e.g., that regards beneficiaries as active members of the supply chain) have been proposed as solutions incorporating social aspects (Kovács and Spens 2011a). A sustainable economic approach requires local rather than global partnerships in order to respect local businesses (Matopolous et al. 2014). Regarding the environmental aspect, the greening of humanitarian supply chains is not straightforward and there is still a gap in this practice (Haavisto and Kovács 2014). Barriers to greening humanitarian supply chains include inadequate information, communication, coordination, performance management systems, resources, and funding; limitations on political activities; and demand uncertainty (Sarkis et al. 2012). Topics related to the greening of humanitarian supply chains, e.g., transportation emissions, are particularly under researched (Kovács and Spens 2011a).

Most of the sustainable sourcing literature that investigates the impacts of local sourcing versus international sourcing on environmental and/or social impacts is conducted on the food industry. For example, Avetisyan et al. (2014) researched ruminant products in the UK and found that domestic sourcing is preferred to international sourcing only when implemented in regions with relatively low emission intensities. Another study in the food sector (Michalsky and Hooda 2015) confirms that producing locally (in this case, fruits and vegetables) can generate more favorable environmental outcomes (i.e., less greenhouse gas emissions) than sourcing internationally. Hendry et al. (2015) researched the social impacts of local sourcing/buying on food supply chains and concluded that local sourcing is not always favorable as several challenges must be tackled.

\subsection{Life cycle sustainability analysis}

Sustainability assessment methods such as life cycle assessment have been extensively applied in the building sector (e.g., Saner et al. 2013; Cabeza et al. 2014), energy and waste management (Quek and Balasubramanian 2014), packaging (Von Falkenstein et al. 2010), and the food and agri-food sector (Amani and Schiefer 2011). To the best of our knowledge, Oberhofer et al. (2015) conducted the only LCA in the humanitarian sector, when they analyzed the supply chain of the French Red Cross ${ }^{1}$ to calculate the carbon footprint of three commonly used relief items (blanket, plastic sheet, and jerry can). However, there is a growing need to focus on all

\footnotetext{
${ }^{1}$ Based on keyword searches that included "humanitarian," "logistics," "supply chain management," "operations," "sustainability analysis," "LCA," and a combination of those.
}

three sustainability dimensions (people, planet, and profit) when assessing sustainability. The LCSA is a transdisciplinary framework; rather than a single prescriptive model, it consists of multiple models and guidelines (Guinée et al. 2011). Using a combination of LCA, social life cycle analysis (S-LCA), and life cycle costing (LCC) is recommended, even if harmonizing results across the three models is challenging (Klöpffer 2008; Curran 2012). For recent comprehensive reviews of S-LCA, see Petti et al. (2016) and Wu et al. (2014). The latter conclude that "workers" are the most researched stakeholder group. Life cycle costing techniques have been applied, among others, within the context of waste management (MartinezSanchez et al. 2015). To the best of our knowledge, no literature exists on S-LCA and LCC in the humanitarian context.

\section{Methodology}

In order to better understand sustainability impacts in humanitarian supply chains, we conducted a case study. Case studies are well fitted to such exploratory research (Eisenhardt 1989; Handfield and Melnyk 1998; Meredith 1993; Voss et al. 2002). Although case studies have limitations, we followed well-established methodological guidelines (Eisenhardt 1989; Flynn et al. 1990; Meredith 1993; Voss et al. 2002; Yin 1994) to increase the validity of our findings. We studied one organization in-depth, which allowed us to obtain multiple types of evidence (qualitative through interviews and quantitative through data). We applied a methodological framework based on the ISO 14040 guidelines for LCA, as described by Curran (2012). Below we describe each step to further explain our methodology.

\subsection{Goal, functional unit, system boundaries, and data}

The goal of this project is to evaluate two sourcing alternatives for a kitchen set supplied by UNHCR by conducting an LCSA. A kitchen set is considered to be a Core Relief Item as it is life sustaining for beneficiaries in that it is required to fulfill their basic needs (UNHCR 2015). A kitchen set enables the storing and cooking of food and water. Moreover, if all else fails, kitchen set elements can serve as makeshift tools (e.g., for digging or cutting). Kitchen sets account for $1.11 \%$ of UNHCR annual procurement volume and $2.62 \%$ of annual total procurement costs (the sixth highest). Kitchen sets are procured globally (via international sourcing) and locally.

We focus on stainless steel as this is the core material used in the cooking and serving utensils of kitchen set type B, approved and preferred by UNHCR (see Core Relief Items Catalogue, third Edition, February 2012). The generic endto-end product cycle of the kitchen set, as well as the scope of our analysis, is displayed in Fig. 1. We exclude raw material extraction and steel manufacturing (i.e., metal production 


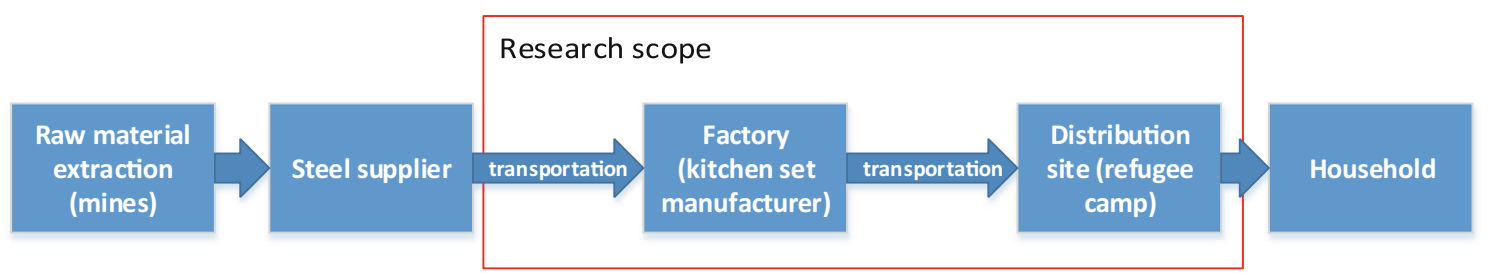

Fig. 1 Generic end to end product cycle (source: UNHCR)

from ore) from our scope as we determined, based on interviews within UNHCR and with suppliers, that in the case of both production in India and local production in Kenya raw materials are sourced from India. Similarly "household" use, reuse, and waste are outside of the scope of this project since it is reasonable to assume that these remain unchanged across sourcing scenarios. The supply chain phases within scope are inbound transportation of the steel materials to the factory, production of the kitchen set at the factory, and outbound transportation of the final product to the refugee camp sites.

Our study focuses on a kitchen set distributed to two large refugee camps in Kenya, Dadaab and Kakuma. We selected the only UNHCR supplier in Kenya for our local sourcing scenario. We selected India as the manufacturing country of interest for our international sourcing scenario because it accounts for the largest share (54\%) of kitchen set procurement volume of UNHCR. The supplier of interest was then selected based on procurement volume (41\%). The selected kitchen set suppliers' supplier, i.e., the party that supplies steel rolls, is one of the largest in India. The supplies were assumed to be shipped by train, as the majority of materials shipped from this supplier are transported by rail (The Economic Times 2014). Data for environmental life cycle assessment and life cycle costing were obtained through a data collection form adapted from Curran (2012) (see Supplement 4, Electronic Supplementary Material) and sent to the UNHCR suppliers of interest. In both the international and local sourcing scenarios, the kitchen sets are fabricated in a similar technological process. Based on distances between the steel supplier, the manufacturing sites, and the refugee camps in Kenya, transportation emission outputs were estimated using the EcoTransIT tool. We used the Ecological Transport Information Tool for Worldwide transports ${ }^{2}$ because it includes a detailed and accurate database (Ehrler and Seidel 2014; Auvinen et al. 2014), is widely adopted (see, e.g., Fries and Hellweg 2014), and aligns with European standards (EN 16258) for the calculation of transport emissions (EcoTransIT 2016). The boundaries of the EcoTransIT tool are determined by the inputs which are vehicle/vessel type, size, and weight; capacity utilization (load factor, empty trips); total weight of freight; and transport distance. These inputs are the main factors influencing the energy and emissions of

\footnotetext{
$\overline{2}$ For guidelines of the EcoTransIT tool, we refer to: http://www.ecotransit. org/download/EcoTransIT_World_Methodology_Report_2014-12-04.pdf.
}

freight transport (EcoTransIT 2016). The calculations were based on the following:

- Road transport: 26-40-t truck; emission factor EURO 5; loading factor $80.0 \%$ (outbound transport from kitchen set supplier to refugee camps); loading factor $100 \%$ (inbound transport from steel supplier to kitchen set supplier); empty trip factor $20 \%$

- Sea transport: ship type "other global trade" (35-120 k $\mathrm{dwt}$ ); loading factor $55.0 \%$; speed utilization $75 \%$

- Rail transport: diesel; coal and steel train; loading factor $100 \%$; empty trip factor $100 \%$

Inputs for these have been verified with UNHCR to ensure they are representative.

Data for the social life cycle assessment were obtained via interviews with the suppliers, online (statistics) databases (among others, those of UNICEF and the International Labour Organization (ILO)), and additional company or government online resources. There are no established standards for social life cycle assessment (Petti et al. 2016). We followed the United Nations Environment Programme (UNEP)/Society for Environmental Toxicology and Chemistry (SETAC) guidelines (UNEP/SETAC 2009) on subcategories and indicators for assessing social impacts (see Supplement 1 section 2 and Supplement 2 section 2, Electronic Supplementary Material), as these are common for performing such an analysis (see, e.g., Ciroth and Franze 2011).

\subsection{Assessment methods}

\subsubsection{Environmental assessment}

To assess environmental impacts, we used the ReCiPe method developed by Goedkoop et al. (2013). We adopted the hierarchist version of the method because it has a balanced time perspective and is the one most often applied (Goedkoop et al. 2013; Margni and Curran 2012). The ReCiPe method models impacts at both mid- and end point levels and is among the recommended LCIA methods, based on criteria such as completeness of scope, scientific robustness, and applicability (Hauschild et al. 2013). It consists of 18 midpoint categories, among them climate change and marine eutrophication (for a complete list, please refer to Supplements 1 and 2, Electronic Supplementary Material). These midpoint impacts 
are linked to three endpoint impacts - damage to human health, damage to ecosystem diversity, and damage to resource availability — through the following formula:

$I_{e}=Q_{e m} I_{m}$

In this formula, $I_{m}$ is the indicator result for midpoint impact category $m$ (e.g., impact on climate change); $Q_{e m}$ is the characterization factor that connects midpoint impact category $m$ with endpoint impact category, $e$; and $I_{e}$ is the indicator result for endpoint impact category $e$ (e.g., damage to ecosystem diversity) (Goedkoop et al. 2013). The characterization factor $Q_{e m}$ is known based on the ReCiPe template developed by Goedkoop et al. (2013) and is considered to be a weighting factor. The indicator result for endpoint impact category $I_{e}$ becomes especially meaningful when comparing different scenarios.

\subsubsection{Social assessment}

For our analysis, we chose the method developed by UNEP/ SETAC (2009) to operationalize social assessments because this method avoids cause-effect chains between impact categories that are unknown or ambiguous (Parent et al. 2010). Based on the subcategory/indicator, the data collected is either at the company or sector/country level. Lack of data harmonization in S-LCA is still an unsolved issue (Wu et al. 2014). Regarding company-specific data, it is generally accepted in S-LCA that the performance of the company is assessed, rather than that of the functional unit of the LCA study itself ( $\mathrm{Hu}$ et al. 2013).

There are no internationally accepted methods for determining whether the aspects found in the inventory analysis have a positive or a negative social impact for the various relevant stakeholders (Ciroth and Franze 2011; UNEP/SETAC 2009). We adopt the method of Ciroth and Franze (2011) to assess and visualize these impacts. This method seems appropriate for our case as it uses a multilevel scoring system and applies equal weighting to the various stakeholder groups involved. In contrast to the LCA, the social information of the S-LCA is evaluated by a scoring system, which attempts to assess the "meaning" of the data. This provides an estimation of the impact (UNEP/SETAC 2009). The assessment process consists of two phases. In the first phase of performance assessment, the performance of the sector/company is assessed by ranking the indicators, per subcategory, from very good performance (1) to very poor performance (6). Next, to move from performance assessment (PA) to impact assessment (IA), the impacts of the subcategory performances are categorized as either rather high $(+)$ or rather low $(-)$ on the UNEP/SETAC impact categories (this is context dependent), and impacts are also ranked from positive effect (1) to very negative effect (6). Last, using subcategory scores, averages are calculated per stakeholder group. We adopted the rules of Ciroth and Franze (2011) to calculate the average scores ${ }^{3}$ and all subcategories were weighted with the same factor.

\subsubsection{Economic assessment}

For the life cycle costing analysis, we include only internal costs of the production and transportation stages. According to Rebitzer and Hunkeler (2003), an LCC must focus only on the economic system (internal costs) if "LCC is applied in conjunction with environmental and/or social assessments for the same product system with the same system boundaries" (pp. 254). We therefore assume that all external costs are covered by the environmental and social LCA. As we take the perspective of the buyer (UNHCR), who must make the sourcing trade-off, we take all landed costs covered by the buyernamely, product procurement costs and transportation costs. Because actors across the two supply chains (sourcing scenarios) may have different profit margins, we acknowledge that differences between the two sourcing strategies in terms of their product procurement costs and transportation costs may not reflect differences in the actual costs of transforming raw materials into a final product and transporting that product to the beneficiaries. Moreover, such cost differences will also depend on actual cost allocation mechanisms. So for the economic assessment, we consider only procurement costs (in which production costs are covered) and transportation costs.

In conclusion, the methodological steps of the LCSA for both the international and the local sourcing scenarios are (in order) environmental LCA, social LCA, and LCC. Next, results of the scenarios are compared in the interpretation (see Fig. 2).

\section{Inventory analysis and impact assessment}

We present a summary of results below in Table 1 (international sourcing scenario) and Table 2 (local sourcing scenario). A comprehensive overview of additional environmental, social, and economic inventory data and sources of our analysis are provided in Supplement 1 (international sourcing scenario) and in Supplement 2 (local sourcing scenario). Calculation details on the environmental LCA are provided in Supplement 3 (Electronic Supplementary Material).

\subsection{International sourcing scenario: environmental LCA}

The production process comprises the manufacturing of a kitchen set in India. The scrap is not recycled. Furthermore, no emissions to air or water are reported. Results show that to

\footnotetext{
${ }^{3}$ For an elaboration on the methods of the social impact assessment and an example, we refer to Supplement 1 (section 2) and Supplement 2 (section 2).
} 


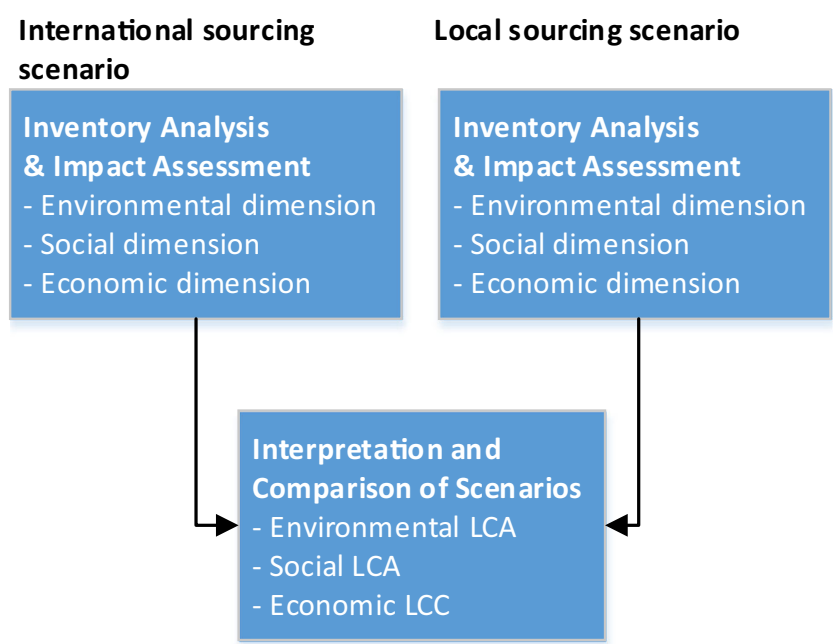

Fig. 2 Methodological steps

produce $1 \mathrm{t}$ of kitchen sets (which corresponds to 1000 sets), $3923 \mathrm{~kg}$ of $\mathrm{CO}_{2}$ is emitted. In the production phase, $99 \%$ of the endpoint impacts are related to human health according to the ReCiPe analysis (see Supplement 3, Electronic Supplementary Material).

Table 1 Overview of international sourcing scenario
Steel materials are shipped from the steel manufacturing site (Jamshedpur) to the kitchen set manufacturer by train via Mumbai (last-mile delivery by truck). Finished goods are shipped in corrugated boxes from the factory to the port of Mumbai (India) by truck and then dispatched by sea to, among other locations, Kenya (Port of Mombasa). Last-mile delivery to refugee sites Kakuma and Dadaab takes place by truck. Based on the ReCiPe analysis, we can observe that the main midpoint impacts of this transportation mode mix are on the areas of climate change $\left(\mathrm{CO}_{2}\right)$, marine eutrophication $\left(\mathrm{NO}_{x}\right)$, and terrestrial acidification $\left(\mathrm{SO}_{2}\right)$ (see Supplement 1 , Electronic Supplementary Material), with climate change being the greatest of these.

In total, the production phase accounts for $97 \%$ of the impacts related to climate change whereas the transport phase accounts for only $3 \%$. The endpoint impacts are observed mainly in the human health impact category.

\subsection{International sourcing scenario: social LCA}

Workers The Indian steel manufacturing sector is characterized by a large number of trade unions (Singh 2008).

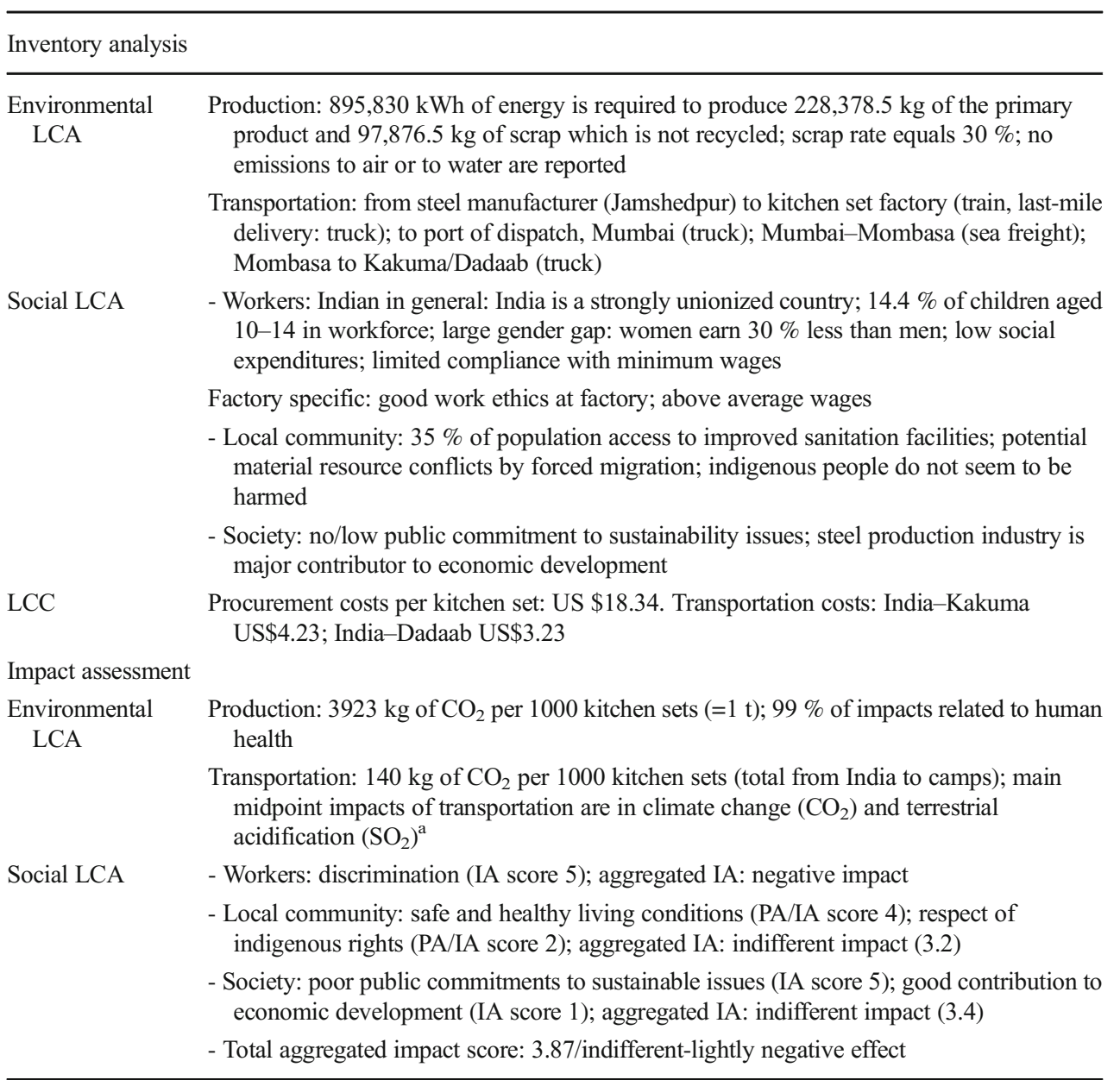


Table 2 Overview of local sourcing scenario

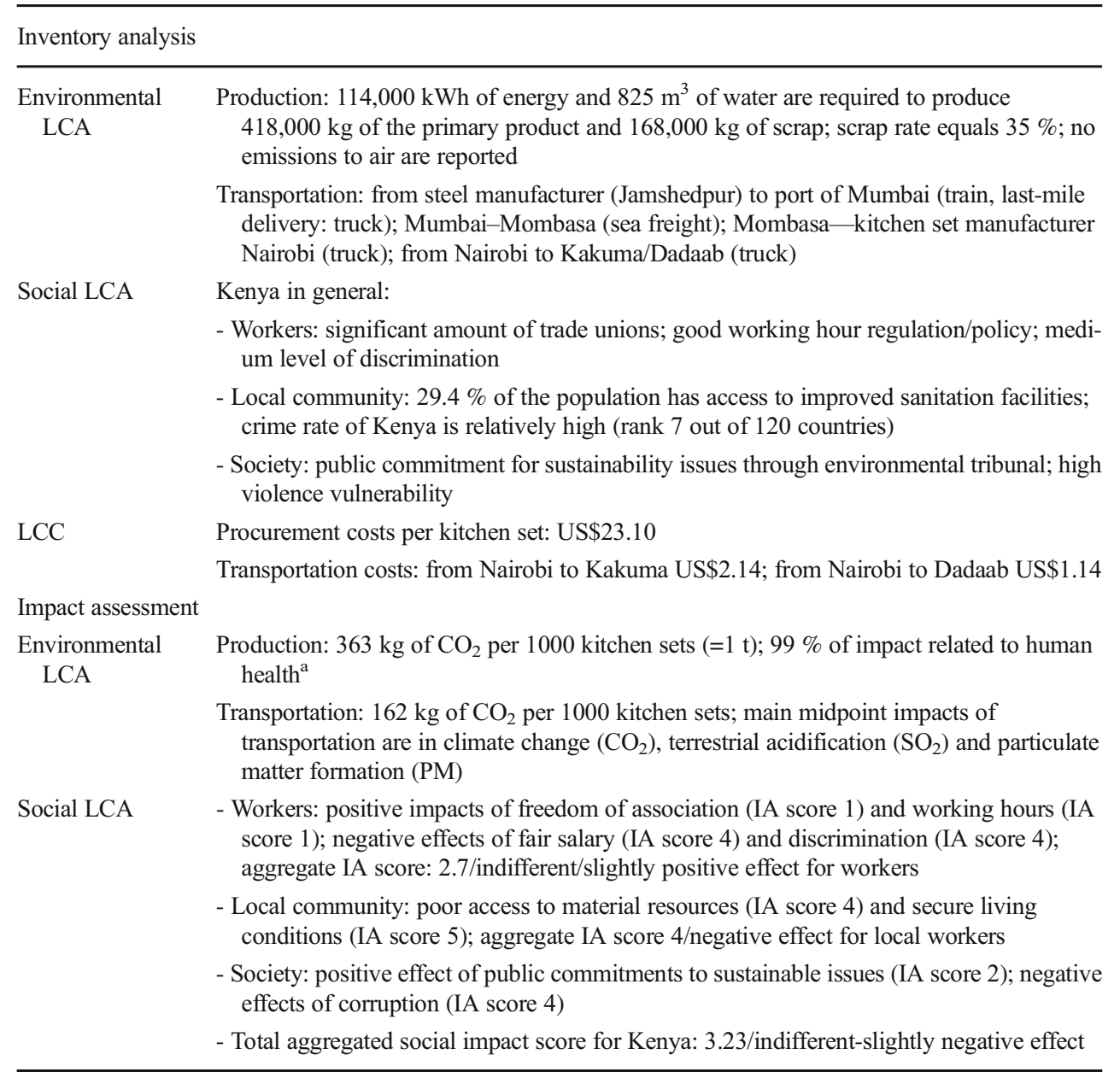

However, it is unclear the extent to which they are effective as some suffer from inter-union competition and financial instability. Cases of child labor and forced labor are not found in the steel pot manufacturing industry; however, on average, $14.4 \%$ of children ages $10-14$ are in the work force (ILO 2015). In India, compliance with minimum wages is generally low (ILO 2014). Moreover, the gender wage gap is quite significant and women earn approximately $30 \%$ less than men. Additionally, social security expenditures in India are quite low. According to company data, working conditions in the steel pot plant in India are above the sector/country averages presented in the information above. The working conditions are reasonably good, as the supplier guarantees good work ethics (though specific examples are not provided by the company) (Alpinter 2015).

Local community The local community is mainly impacted by limited access to material and immaterial resources. In India, $35 \%$ of the population has access to adequate sanitation facilities. The Ministry of Steel has planned projects to improve infrastructures as steel transport relies heavily on these. Potential material resource conflicts can arise when people are forced to leave their land; however, the indigenous people do not to seem to be at risk of this since the north, where they are living, is not an iron mining area.

Society There does not seem to be a public commitment to sustainability issues. There are no direct signs that the supplier applies codes of conducts (Alpinter 2015). The economic contribution of the steel pot manufacturing sector is unclear. India is the world's fourth largest steel producer. The steel production industry seems to make a major contribution to the Indian economy and its GDP growth of $3.2 \%$. Because of mining activities, there is a risk of land acquisition conflicts.

Impacts are determined based on this social inventory data using the method described in Ciroth and Franze (2011) (see chapter 3, "Methodology" section; see Supplement 1, section 2, Electronic Supplementary Material). With regard to the worker stakeholder group, i.e., specifically on matters of child labor, fair salary, and forced labor, the company/sector 
perform well (PA score 2). ${ }^{4}$ Regarding discrimination, the sector performs poorly (PA score 5), which results on average in an inadequate overall performance (PA score 4). As the poor performance on discrimination contributes to all impact categories, the impact on the end result (IA score 4) is quite significant.

Concerning the stakeholder group local community, the rather poor performance (PA score 4) and negative impact (IA score 4) of safe and healthy living conditions and the rather good performance with respect to indigenous rights (PA score 2) and positive impact (IA score 2) result in an average IA score of 2.9 (slightly positive/indifferent effect).

Lastly, when considering society, the poor public commitments to sustainability issues (PA score 4), the negative impact of prevention and mitigation of conflicts (IA score 4), and very positive effect of contribution to economic development (IA score 1) result in an aggregate lightly negative effect for society (score 3.4 ).

\subsection{International sourcing scenario: LCC}

The procurement cost of the Indian kitchen set is US\$18.34. The transportation cost per unit for India-Kakuma and IndiaDadaab is US\$4.23 and US\$3.23, respectively (see Supplement 1 for more details on transport costs, Electronic Supplementary Material).

\subsection{Local sourcing scenario: environmental LCA}

The production process comprises the manufacturing of a kitchen set in Kenya. No solid wastes or emissions to air are reported. However, treated water is reported as emissions to water, based on estimates by engineers. To produce $1 \mathrm{t}$ of kitchen sets, only $363 \mathrm{~kg}$ of $\mathrm{CO}_{2}$ is emitted, resulting in climate change midpoint impacts and main endpoint impacts on human health. Regarding transportation, steel materials are shipped from the steel manufacturing site in India to Mumbai harbor by train (last-mile by truck), then dispatched by sea to Kenya (Port of Mombasa). Subsequently, the steel materials are transported by truck to the kitchen set supplier in Nairobi where the kitchen sets are manufactured. Last-mile delivery to refugee sites (Kakuma and Dadaab) takes place by truck. Based on the ReCiPe analysis, the midpoint impacts of transportation are in the areas of climate change $\left(\mathrm{CO}_{2}\right)$, terrestrial acidification $\left(\mathrm{SO}_{2}\right)$, and particulate matter formation (PM), with the dominant being climate change (see Supplement 2, Electronic Supplementary Material). The contribution of the production phase to climate change is $69 \%$ and that of transportation phase is $31 \%$. The endpoint impacts are mainly observed in the human health impact category.

\footnotetext{
${ }^{4}$ For a more elaborate overview of the meaning of the rankings, we refer to Supplement 1.
}

\subsection{Local sourcing scenario: social LCA}

Workers The Kenyan industry sector has a significant number of trade unions and they seem to be quite successful in negotiating collective agreements. With regard to working time, employees are entitled to have 24 consecutive hours of rest per week and a regular work week is $52 \mathrm{~h}$. Overtime is restricted to a maximum of $6 \mathrm{~h}$ per week and employers must pay overtime to their employees equal to at least $150 \%$ of the wage. There is a medium level of discrimination in the country. At the sector level, women earn $8 \%$ less than men, on average; and in the manufacturing industry only $26.3 \%$ of the workforce is female. At the factory in Kenya men and women are paid the same.

Local community As regards local community indicators, the steel industry encompasses about $13 \%$ of the manufacturing sector. Because no raw materials are extracted locally, however, the local steel industry depends on imported raw materials. Only $29.4 \%$ of the population has access to adequate sanitation facilities. Potential material resource conflicts could arise as conflicts in Kenya revolve around land issues; however, conflicts in Kenya currently stem primarily from differing community identities. Lastly, the crime rate in Kenya is relatively high compared to other countries.

Society Concerning public commitment to sustainability issues, it is notable that a National Environmental Tribunal has been in force since 1999 and is highly successful according to the United Nations. The supplier in Kenya, however, does not seem to be strongly committed as it did not sign any codes of conduct with regard to this matter. Kenya has reasonable GDP growth of $5.1 \%$. The general country profile shows that Kenya has been disturbed by corruption and that Kenya's long-term position will be influenced by the extent to which its infrastructure is properly developed. Furthermore, Kenya is vulnerable for violence because of its proximity to Somalia and Sudan, which are known for the violent terrorist groups $\mathrm{Al}$ Shabaab and Al Qaeda. Land use issues revolve around natural resources, such as oil, metals, and water; however, these do not seem to relate directly to the steel manufacturing sector.

Once again, we assess impacts from the social inventory data using the method described in Ciroth and Franze (2011). Regarding the performance assessment of the worker stakeholder group, with respect to "freedom of association" and "working hours," the company/sector performs well (PA score 2). Performance regarding "fair salary" is satisfactory (PA score 3) and performance regarding "discrimination" (PA score 4) is quite poor, resulting in negative impact scores for these two categories (IA score 4). In aggregate, the social impacts for workers are indifferent/lightly positive (IA score 2.6). As concerns the stakeholder group local community, 
very poor performance on access to material resources (PA score 5) and secure living conditions (PA score 6) result in aggregate negative social impacts for local community (IA score 4). Lastly, with regard to society, effects of public commitments are positive (IA score 2) and negative for corruption (PA score 5; IA score 4). Aggregating the social impacts of the three groups of stakeholders results in a social impact score of 3.23 for local sourcing in Kenya; this implies an indifferentlightly negative effect.

\subsection{Local sourcing scenario: LCC}

Products are shipped directly from the supplier to the destination camps, Kakuma and Dadaab. The procurement cost of a kitchen set is US\$23.10. The transportation costs per unit for Nairobi-Kakuma and Nairobi-Dadaab are US\$2.14 and US\$1.14, respectively (see Supplement 2, section 3 for more details on transport costs, Electronic Supplementary Material).

\section{Interpretation}

\subsection{Environmental profile}

The environmental profile of the international sourcing scenario for kitchen sets is strongly dominated by the production phase, and the main midpoint impact is climate change. Likewise, the main impacts for the transportation phase are also related to climate change. In converting midpoint impacts to endpoint impacts, human health is most affected by the production and transportation of the kitchen set.

The production phase also dominates the environmental profile of the local sourcing scenario for the kitchen set but to a lesser extent. For the impact categories, this results in the greatest impact on climate (midpoint category) and damage to human health (endpoint category). No endpoint impact could be calculated for water depletion in the production stage; however, we observe that water depletion accounts for only a small percentage of impact on the environment (see Supplement 3, Electronic Supplementary Material).

Comparing the environmental profile of the two scenarios, we can observe that the local sourcing option outperforms the international one with respect to production impact. Energy consumption is relatively low; accordingly, so too is $\mathrm{CO}_{2}$ emissions per kitchen set. The higher efficiency of the factory in Kenya may be due to economies of scale (production volume is approximately $26 \%$ higher than at the factory in India) and to differences in production technology. The international sourcing scenario performs slightly better with respect to transportation environmental impacts. This is mainly due to lower scrap rates and higher proximity to the steel supplier, which result in smaller amounts of steel materials being transported over a shorter distances and, hence, lower emission rates.

\subsection{Social profile}

For each sourcing option, we identified social hotspots (i.e., categories with serious negative impacts or poor performance) for each of the analyzed stakeholder groups. In the international sourcing scenario, the stakeholder group "workers" is the worst affected. This is mainly due to the presence of (gender) discrimination (among others, gender and ethnicity are sometimes a criterion for hiring employees resulting in a low rank on the country gender index; see Supplement 1, section 2, Electronic Supplementary Material) despite codes of conducts and government initiatives. Overall, local community and society are slightly negatively affected. A major social hotspot is the category of living conditions, which are not very safe or healthy (a.o. the burden of disease and the pollution level in the country are high; see Supplement 1, section 2, Electronic Supplementary Material). Concerning the society stakeholder group, public commitment to sustainability issues is very low, and we did not find evidence of publicly available promises or agreements on sustainability issues.

According to the impact assessment when goods are produced locally (in Kenya), workers are the least affected as compared to other stakeholder categories. This is mainly because there are ratified conventions and laws in place that protect workers. Major areas of concern are discrimination and social benefits. Based on the impact assessment, local community seems to be the worst affected. Social hotspots are the access to material resources (as only a small part of Kenyans have access to improved sanitation facilities) and secure living conditions. Secure living conditions are rated relatively low due to the high crime rate in the country. The stakeholder group society performs slightly negative. The main reason for this is that corruption in the country is high.

Comparing the social profile of the two scenarios, we conclude that the local sourcing scenario outperforms the international sourcing scenario with respect to stakeholder groups, workers, and society. The international sourcing scenario scores higher with respect to local community. The main reason international sourcing performs worse with respect to workers is the relatively low score in discrimination: discrimination in India is worse than in Kenya as gender and ethnic background are more often a criterion for (not) hiring an employee. The lack of secure living conditions in Kenya is the main reason the local sourcing scenario scores lower on local community. Finally, when looking at the stakeholder group society, the relatively high commitment to sustainability issues in Kenya makes the local sourcing scenario more favorable to the international sourcing scenario. 


\subsection{Life cycle costs}

Based on the LCC, procurement costs are the largest part of the total landed costs in both scenarios. Transportation costs are double when it comes to international sourcing, due to the long distance from India to Nairobi (Kenya). However, savings in procurement costs outweigh additional transportation expenses, making international sourcing the lowest overall cost option.

\section{Discussion}

Comparing the two LCSA analyses, we can conclude that there is not one scenario that outperforms the other on every aspect (see Table 3, favorable results are in italics; see Supplement 2 and Fig. 5, Electronic Supplementary Material). We can conclude that the local sourcing scenario has better results for the production stage, for total environmental impact assessment, for social impact assessment related to workers and society, and for the aggregated social impact. It should be noted, however, that differences between social outcomes for both scenarios are not very large and that Kenya's impacts are on average "indifferent" (see Table 3). Additionally, total landed costs are higher when procuring locally.

Having highlighted and quantified these trade-offs, the UNHCR can make better informed decisions. Choosing between the two scenarios will result in emphasizing different aspects in the supply chain, either in terms of more favorable economics (international sourcing) or in terms of more favorable environmental and social impacts (local sourcing). Schneider and Wallenburg (2012) identify different sustainability sourcing profiles/archetypes. In the case presented below, when choosing for international sourcing, the organization would be an "economist"-focusing mainly on economic performance and having minimum acceptable performance levels with respect to the environment and the society. Adopting the local scenario, the "social environmentalist" archetype would apply because more environmentally and socially friendly outcomes are emphasized (Schneider and Wallenburg 2012). Schneider and Wallenburg (2012) further argue that these archetypes are valuable in conceptualizing sustainable sourcing and can serve as a starting point to move to the "all-round perfectionist" type organization that emphasizes all three pillars of the triple bottom line of sustainability (depending on context and stakeholder salience). The analysis also highlights opportunities for improvement. For example, UNHCR could, based on performance across the three dimensions, decide to help its Kenyan supplier become more efficient with respect to reducing its scrap rate in order to reduce both emissions in the transportation phase and material costs. Another option for UNHCR could be to help its Indian (i.e., international) supplier improve energy efficiency in order to cut emissions at the production stage.

Overall, this study confirms previous studies in the (commercial) food sector advocating local sourcing for environmental reasons (Avetisyan et al. 2014; Michalsky and Hooda 2015). At the same time, food supply chains are different from humanitarian supply chains: specifically, humanitarian supply chains differ with respect to resource and supplier availability, governance structures, and donor requirements. Moreover, reviewed food sector studies have focused on only one aspect of sustainability (either environment or society), while our study assesses environmental, social, and economic impacts of international sourcing versus local sourcing.

\section{Conclusions}

This study provides a sustainability analysis of two procurement scenarios for a core relief item in a humanitarian supply chain. We presented an LCSA consisting of three separate assessments: environmental life cycle assessment, social life cycle assessment, and life cycle costing. We applied LCSA and found that a local sourcing scenario outperforms an international sourcing scenario with respect to environmental and social impacts.

This study contributes to the academic literature by (a) taking an inclusive sustainability approach, covering all three aspects of the triple bottom line (people, planet, profit), thereby using a framework that is relatively new in the literature; (b) conducting research in a humanitarian supply chain context, thereby contributing to the relatively young field of sustainable humanitarian supply chain management and logistics; and (c) conducting research within the context of emerging economies.

Our paper also has practical implications. NGOs can use this approach to identify environmental, social, and economic impacts of their relief item supply chains. Our analysis may serve as a starting point for future benchmarking or for reconsideration of humanitarian supply chains. Furthermore, it may facilitate an evaluation of policies related to the goals of NGOs (e.g., to be more environmentally or socially sustainable or both?) and help them align their supply chain designs with socioeconomic context of their operations (as proposed by Kunz and Gold 2015). Furthermore, our work may serve as an example of how to analyze a supply chain with regard to sustainability; identify the environmental, social, and economic hotspots in operations; and classify an NGO according to the framework of Schneider and Wallenburg (2012) in order to determine future actions. Last, an LCSA analysis may help humanitarian organizations communicate about their supply chain design with their donors. Humanitarian organizations are quite dependent upon 
Table 3 Comparison of LCSA scenarios

\begin{tabular}{llll}
\hline & & $\begin{array}{l}\text { International sourcing } \\
\text { India }\end{array}$ & $\begin{array}{l}\text { Local sourcing } \\
\text { Kenya }\end{array}$ \\
\hline Environmental LCA (endpoint impacts) & Production-HH & 0.00549159 & 0.00050909 \\
& Production-ED & 0.00003110 & 0.00000288 \\
& Transportation-HH & 0.000215188 & 0.00025134 \\
& Transportation-ED & 0.00000111 & 0.00000129 \\
Social LCA (IA scores) & Workers & 5 & 2.7 \\
& Local community & 3.2 & 4 \\
& Society & 3.4 & 3 \\
& Procurement costs/unit & US\$18.34 & US\$23.10 \\
\hline
\end{tabular}

$H H$ damage to human health (unit: disability-adjusted loss of life years), $E D$ damage to ecosystem diversity (loss of species during a year; see Goedkoop et al. 2013) donations and donor requirements (Haavisto and Kovács 2012). This study shows that financial considerations do not necessarily align with environmental and social considerations; thus, analyses need to take into account more than economic aspects.

The study has some limitations. First, the focal suppliers collected the environmental data; therefore, our influence on data quality reporting bias was limited. Furthermore, the accuracy of the social analysis is debatable, as data of different functional units were collected for the different subcategories (though this was mainly caused by the nature of the indicator). As far as we know, there are no standards for social assessment; thus, choices may be subjective. We have tried to overcome this by discussing the assessment within the author team. Future LCSA research could involve consulting experts who are highly informed about the social circumstances in a specific country or sector (in addition to using online databases for data collection) or asking several persons to conduct the same impact assessment and then calculating the average of their assessments to arrive at a final assessment. A final note should be made to decision makers who want to use LCSA for determining their sourcing scenario: they should take into account the environmental dynamics with respect to social impacts as these can change over time, thereby influencing the attractiveness of certain sourcing options.

Several directions for future research can be derived. First, the LCSA framework and the corresponding three assessments should be further refined. The social impact assessment method, in particular, should be researched and developed in order to establish common standards and strengthen its reliability. In addition, further research on sustainability in humanitarian supply chains is required in order to improve the level of preparedness of relief organizations.

This paper is a first step in developing a better, more empirically grounded understanding of sustainability in humanitarian supply chains. Interest in sustainable humanitarian logistics will only grow in the coming years. This and future research on analyzing and improving sustainability in humanitarian supply chains is key to "alleviate the suffering of vulnerable people".

Open Access This article is distributed under the terms of the Creative Commons Attribution 4.0 International License (http:// creativecommons.org/licenses/by/4.0/), which permits unrestricted use, distribution, and reproduction in any medium, provided you give appropriate credit to the original author(s) and the source, provide a link to the Creative Commons license, and indicate if changes were made.

\section{References}

Alpinter (2015) Retrieved 01-05-2015 from http://alpinter. com/production.html

Amani P, Schiefer G (2011) Review on suitability of available LCIA methodologies for assessing environmental impact of the food sector. Int J Food System Dynamics 2(2):194-206

Apte A (2010) Humanitarian logistics: a new field of research and action (vol. 7). Now Publishers Inc.

Auvinen H, Clausen U, Davydenko I, Diekmann D, Ehrler V, Lewis A (2014) Calculating emissions along supply chains - towards the global methodological harmonisation. Research in Transportation Business \& Management 12:41-46

Avetisyan M, Hertel T, Sampson G (2014) Is local food more environmentally friendly? The GHG emissions impacts of consuming imported versus domestically produced food. Environ Resour Econ 58(3):415-462

Balcik B, Ak D (2014) Supplier selection for framework agreements in humanitarian relief. Prod Oper Manag 23(6):1028-1041

Cabeza L, Rincón L, Vilariño V, Pérez G, Castell A (2014) Life cycle assessment (LCA) and life cycle energy analysis (LCEA) of buildings and the building sector: a review. Renew Sust Energ Rev 29: 394-416

Ciroth A, Franze J (2011) LCA of an ecolabeled notebook-consideration of social and environmental impacts along the entire life cycle. Berlin, Germany, GreenDeltaTC

Curran MA (ed) (2012) Life cycle assessment handbook: a guide for environmentally sustainable products. John Wiley \& Sons, USA 
Davis LB, Samanlioglu F, Qu X, Root S (2013) Inventory planning and coordination in disaster relief efforts. Int J Prod Econ 141(2):561573

Duran S, Ergun Ö, Keskinocak P, Swann JL (2013) Humanitarian logistics: advanced purchasing and pre-positioning of relief items. Handbook of global logistics, pp 447-462

EcoTransIT (2016) EcoTransIT: Ecological Transport Information Tool for Worldwide Transports. http://www.ecotransit.org/index.de.html.

Ehrler VC, Seidel S (2014) A standardisation of the calculation of CO2 (e) emissions along supply chains: challenges and requirements beyond EN 16258. In: Information technology in environmental engineering. Springer, Berlin Heidelberg, pp 191-200

Eisenhardt KM (1989) Building theories from case study research. Acad Manag Rev 14(4):532-550

Ertem MA, Buyurgan N, Rossetti MD (2010) Multiple-buyer procurement auctions framework for humanitarian supply chain management. Int J Phys Distr 40(3):202-227

Falasca M, Zobel CW (2011) A two-stage procurement model for humanitarian relief supply chains. J Humanit Log 1(2):151-169

Flynn BB, Sakakibara S, Schroeder RG, Bates KA, Flynn EJ (1990) Empirical research methods in operations management. J Oper Manag 9(2):250-284

Fries N, Hellweg S (2014) LCA of land-based freight transportation: facilitating practical application and including accidents in LCIA. Int J Life Cycle Assess 19(3):546-557

Gimenez C, Sierra V, Rodon J (2012) Sustainable operations: their impact on the triple bottom line. Int J Prod Econ 140:149-159

Goedkoop M, Heijungs R, De Schryver A, Struijs J, Van Zelm R (2013) ReCiPe 2008. A LCIA method which comprises harmonised category indicators at the midpoint and the endpoint level. Characterisation

Golicic S, Smith C (2013) A meta-analysis of environmentally sustainable supply chain management practices and firm performance. J Supply Chain Manag 49(2):78-95

Guinée JB, Heijungs R, Huppes G, Zamagni A, Masoni P, Buonamici R, Rydberg T (2011) Life cycle assessment: past, present, and future. Environ Sci Technol 45(1):90-96

Haavisto I, Kovács G (2012) Sustainability — fad, moral request or donor requirement? In: Supplement to the 2012 Annual Statistical Report on United Nations Procurement. Retrieved 29-03-2015 from https://www.ungm.org/Areas/Public/Downloads/2012 Annual Statistical Report supplement.pdf

Haavisto I, Kovács G (2014) Perspectives on sustainability in humanitarian supply chains. Disaster Prev Manag 23(5):610-631

Handfield R, Melnyk S (1998) The scientific theory-building process: a primer using the case of TQM. J Oper Manag 16(4):321-339

Hauschild MZ, Goedkoop M, Guinée J, Heijungs R, Huijbregts M, Jolliet $\mathrm{O}$, Sala S (2013) Identifying best existing practice for characterization modeling in life cycle impact assessment. Int $\mathrm{J}$ Life Cycle Assess 18(3):683-697

Hendry L, Sayed M, Zorini M (2015) Local buying: the easy answer for sustainable sourcing? Conference paper

Hu M, Kleijn R, Bozhilova-Kisheva KP, Di Maio F (2013) An approach to LCSA: the case of concrete recycling. Int J Life Cycle Assess 18(9):1793-1803

ILO (2014) ILO Global Wage Report 2014/2015 - Asia and the Pacific Supplement. Retrieved 01-05-2015 from http://www.ilo. org/wcmsp5/groups/public/—asia/—ro-bangkok/—srobangkok/documents/publication/wcms 325219.pdf

ILO (2015) International Labor Organization. Retrieved 01-05-2015 from http://www.ilo.org/global/about-the-ilo/media-centre/pressreleases/WCMS 008058/lang-en/index.htm

Klöpffer W (2008) Life cycle sustainability assessment of products (with comments by Helias A. Udo de Haes, p 95). Int J Life Cycle Assess 13(2):89-95
Kovács G, Spens K (2009) Identifying challenges in humanitarian logistics. Int J Phys Distr 39:506-528

Kovács G, Spens K (2011a) Trends and developments in humanitarian logistics - a gap analysis. Int J Phys Distr 41(1):32-45

Kovács G, Spens K (2011b) Humanitarian logistics and supply chain management: the start of a new journal. J Humanit Log 1(1):5-14

Kunz N, Gold S (2015) Sustainable humanitarian supply chain management - exploring new theory. Int J Log Res, pp:1-20

Kunz N, Reiner G (2012) A meta-analysis of humanitarian logistics research. J Humanit Log 2(2):116-147

Margni M, Curran MA (2012) Life cycle impact assessment. In: Curran MA (ed) Life cycle assessment handbook. Wiley, USA, pp. 67-103

Martinez-Sanchez V, Kromann MA, Astrup TF (2015) Life cycle costing of waste management systems: overview, calculation principles and case studies. Waste Manag 36:343-355

Matopolous A, Kovács G, Hayes O (2014) Local resources and procurement in humanitarian supply chains: an empirical examination of large-scale house reconstruction projects. Decision Sci 45(4):621646

Meredith J (1993) Theory building through conceptual methods. Int J Oper Prod Man 13(5):3-11

Michalsky M, Hooda PS (2015) Greenhouse gas emissions of imported and locally produced fruit and vegetable commodities: a quantitative assessment. Environ Sci Pol 48:32-43

Oberhofer P, Blanco EE, Craig AJ (2015) Carbon Efficiency of Humanitarian Supply Chains: Evidence from French Red Cross Operations. Logistics Management, p 53

PAHO (2001) Humanitarian supply Management in Logistics in the health sector. Pan American Health Organization, Washington

Parent J, Cucuzzella A, Revéret J (2010) Impact assessment in SLCA: sorting the sLCIA methods according to their outcomes. Int J Life Cycle Assess 15:164-171

Petti L, Serreli M, Di Cesare S (2016) Systematic literature review in social life cycle assessment. Int J Life Cycle Assess. doi:10.1007 /s11367-016-1135-41-10

Quek A, Balasubramanian R (2014) Life cycle assessment of energy and energy carriers from waste matter-a review. J Clean Prod 79:18-31

Rebitzer G, Hunkeler D (2003) Life cycle costing in LCM-ambitions, opportunities, and limitations, discussing a framework. Int J Life Cycle Assess 8(5):253-256

Saner D, Heeren N, Jäggi B, Waraich R, Hellweg S (2013) Housing and mobility demands of individual households and their life cycle assessment. Environ Sci Technol 47(11):59885997

Sarkis J, Spens K, Kovács G (2012) A study of barriers to greening the relief supply chain. In: Spens K (ed) Relief supply chain management for disasters: humanitarian aid and emergency logistics. Business Science Reference, USA, pp. 196-207

Schneider L, Wallenburg CM (2012) Implementing sustainable sourcing - does purchasing need to change? J Purch Supply Man 18(4): 243-257

Seuring S, Müller M (2008) From a literature review to a conceptual framework for sustainable supply chain management. J Clean Prod 16:1699-1710

Singh BD (2008) Managing Conflict and negotiation. Excel Books, India

Svoboda S (1995) Note on life cycle analysis. National Pollution Prevention Centre for Higher Education

Taupiac C (2001) Humanitarian and development procurement: a vast and growing market. Int Trade Forum 4(1):7-10

The Economic Times (2014) Tata Steel plans to transport steel, coal via waterways. Retrieved 7-7-2016 from: http://articles.economictimes. indiatimes.com/2014-07-17/news/51656927 1 tata-steel-indiakalinganagar-waterways 
Thomas AS, Kopczak LR (2005) From logistics to supply chain management: the path forward in the humanitarian sector. Fritz Institute, San Francisco, CA

UNEP/SETAC (2009) Retrieved 11-05-2015 from http://www.unep. org/pdf/DTIE_PDFS/DTIx1164xPA-guidelines_sLCA.pdf

UNHCR (2015) About us. Retrieved 15-7-2015 from http://www.unhcr. org/pages/49c3646c2.html

Venkatesh VG, Dubey R, Ali SS (2014) Disaster relief operations and continuous aid program in human supply networks: are they congruent? - an analysis. Proceedings of the Third International
Conference on Soft Computing for Problem Solving. pp 959973

Von Falkenstein E, Wellenreuther F, Detzel A (2010) LCA studies comparing beverage cartons and alternative packaging: can overall conclusions be drawn? Int J Life Cycle Assess 15:938-945

Voss C, Tsikriktsis N, Frohlich M (2002) Case research in operations management. Int J Oper Prod Man 22(2):195-219

Wu R, Yang D, Chen J (2014) Social life cycle assessment revisited. Sustainability 6:4200-4226

Yin RK (1994) Case study research: design and methods, 2nd edn. Sage, Newbury Park 